\title{
Impact of Instant Controlled Pressure Drop (DIC) Treatment on Drying Kinetics and Caffeine Extraction from Green Coffee Beans
}

\author{
I. Kamal \\ University of La Rochelle \\ Laboratory of Engineering Science for Environment(LaSIEFRE-CNRS 3474) \\ Avenue Michel Crepeau \\ La Rochelle 17042, cedex 01, France \\ E-mail: imustaph@univ-lr.fr \\ A. Gelicus \\ University of La Rochelle \\ Laboratory of Engineering Science for Environment(LaSIEFRE-CNRS 3474) \\ Avenue Michel Crepeau \\ La Rochelle 17042, cedex 01, France \\ E-mail: anthony.gelicus@univ-lr.fr \\ K. Allaf \\ University of La Rochelle \\ Laboratory of Engineering Science for Environment(LaSIEFRE-CNRS 3474) \\ Avenue Michel Crepeau \\ La Rochelle 17042, cedex 01, France
}

Tel: 33-546-458-766_E-mail: kallaf@univ-lr.fr

Received: October19, 2011

doi:10.5539/jfr.v1n1p24
Accepted: November 4, $2011 \quad$ Published: February 1, 2012

URL: http://dx.doi.org/10.5539/jfr.v1n1p24

\begin{abstract}
The present work is directed towards the impacts of Détente InstantanéeContrôléeDIC (French, for instant controlled pressure-drop) in terms of decaffeination and drying of Ethiopian green coffee beans (GCBs).DICconsisted in subjecting the product to a high-pressure saturated steam during some seconds and ended with an abrupt pressure drop towards a vacuum. A conventional aqueous extraction and a hot air-drying took place after DIC treatment. Inthis study, Response Surface Method (RSM) was used withDIC saturated steam pressure P, thermal treatment time $\mathrm{t}$, and initial moisture content $\mathrm{W}$ asthe independent variables. Both direct DICextract recovered from the vacuum tank and the aqueous extracts wereanalyzed and quantified using the reversed phase-HPLC. With decaffeination ratiosas dependent variables, $\mathrm{P}$ and Wwere the most significant operating parameters; whilet was much weaker.Total decaffeination ratio could reach $99.5 \%$ after DIC treatment at specificconditions of $\mathrm{W}=11.00 \% \mathrm{db}, \mathrm{P}=0.1 \mathrm{MPa}$, and $\mathrm{t}=35 \mathrm{swhile}$ it was only $58 \%$ when achieved with untreated raw material.

The effective diffusivity $D_{e f f}$ and the starting accessibility $\delta W_{s}$ were calculated from the diffusion/surface interaction kinetic model of hotair drying after DIC treatment. They dramatically increased with $\mathrm{P}$ and $\mathrm{t}$ while $\mathrm{W}$ had a weak impact.Thus, at the optimized DICconditions, $D_{o / 2}$ and $8 W_{s}$ increased from 0.33 to $12.6010^{-10} \mathrm{~m}^{2}$ $\mathrm{s}^{-1}$ and from 0.75 to $11.53 \mathrm{~g} / 100 \mathrm{~g} \mathrm{db}$, respectively. Drying time needed to reach $5 \% \mathrm{db}$ became $60 \mathrm{~min}$ instead of $528 \mathrm{~min}$ for untreated raw material.
\end{abstract}


Keywords: Green coffee beans (GCBs), Instant Controlled Pressure Drop (DIC), Drying kinetics, Caffeine extraction, Reversed phase-HPLC, Response Surface Methodology (RSM)

\section{Introduction}

Coffee isthesecondpopular beverageworldwide, and is oneof the mostimportant commodities in international trade. The twowell-known species of coffee trees, which are Coffee Arabica and Coffee Robusta, present high commercial importance. They differ in chemical composition; Arabica contains more lipids and Robusta contains more caffeine and sucrose as well as the polyphenols antioxidant chlorogenic acid and its derivatives(Parliament and Stahl, 1995).

The term "green coffee beans" GCBsrefers to un-roasted mature or immature coffee beans. Caffeine content in green coffee beans varies markedly between species and within species (Robusta vs. Arabica), mainly depending on geographic origins (Rodrigues et al., 2007). It is reported that it ranges from $1.22 \%$ in Arabica to $2.54 \%$ dry basis (or g/100 g of dried coffee) in Robusta (Kyet al., 2001). Huge number of studies focused on coffee, its composition, flavor and quality characteristics (De Maria et al., 1996; De Maria et al., 1994; Sarrazinet al., 2000; Franca et al., 2005).

Caffeine (1,3,7-trimethylxanthine) paid lot of attention. Caffeine is one of the most notorious compounds because of its many physiological effects on the human body, and scientific studies have linked caffeine to the prevention of some related-age disease (Glade, 2010). However, caffeine acts as a central nervous system stimulant and also has negative withdrawal effects (Smith, 2002); as a result, decaffeinated coffee is being used to overcome its negative effects. Thus, from marketing point of view, the decaffeinated coffee green beans have an important economical value. Conversely, it was found that caffeine has had particular interest for pharmaceutical, cosmetic and satiety applications. Both caffeine extract and coffee intakes were modestly and inversely associated with weight gain (James et al., 2006).

Decaffeination processes are usually carried out in order to dramatically reduce the caffeine level.Decaffeinated coffee beverage should reach a caffeine level nearly $0.04 \mathrm{~g} / 100 \mathrm{~g}$ of dried coffee (Fujioka et al., 2008). Literature survey showed huge information on the attempts used for decaffeination. Different factors having an impact on the decaffeination process include blend composition, brewing extraction rates, grind or water temperature (Maeso et al., 2006). Processes such as organic solvent extraction, with or without ultrasound treatment, have been used for decaffeination. However, it is difficult to completely remove the traces of solvent from end-decaffeinatedproducts and the highest level admitted by the international standards is increasingly restrictive (Wang \& Weller, 2006). The final distillation stage would also lead to a great loss of light compounds. Other operations have used the supercritical $\mathrm{CO}_{2}$ as solvent (Icen \& Guru, 2009). Although attractive with low operating costs, the disadvantages of this extraction process are the costly facilities required and a cumbersome installation. Note that supercritical $\mathrm{CO}_{2}$ process as well as microbial and enzymatic methods (Gokulakrishnan et al., 2005) are not selective and can extract not only caffeine but also volatile molecules (Clarke, 2003). The energy costs, together with low kinetics, render the main part of these extraction processes unattractive from an economic point of view.

Other caffeine extraction processes such as microwave-assisted extraction have been proposed (Wang et al., 2011). They offer some advantages regarding kinetics and preservation of the chemical composition, but as far as we know, no industrial development has been achieved and all applications are still at the laboratory scale. No work has used high temperature processes for decaffeination, although such operations would be interesting in coffee industry. Conversely, no steam decaffeination process has been defined or highlighted probably because of the relatively high boiling temperature of caffeine. However, it was noted that the roasting process altered the amount of caffeine in coffee bean. A common misconception is that the darker the roast level, the lower the caffeine content. A small amount of caffeine is lost due to sublimation. This occurs in caffeine at approximately $178^{\circ} \mathrm{C}$,however, thethermodynamic parameters of caffeine have been the subject of various studies (Griesser et al., 1999; Cuong et al., 2010; Emelyanenko \& Verevkin, 2008).

In this context, it was proposed to carry out a study of the possible extraction of caffeine from the Ethiopian Green Coffee Beans GCBs using the innovative technology of Détente InstantanéeContrôléeDIC (French, for instant controlled pressure-drop) through a direct DIC extraction and an intensification of the environmentally friendly aqueous extraction thanks to the DIC-expansion.

DIC was defined in 1988 (Allafet al., 1988) as a high temperature-short time stage usually carried out by establishing high-pressure saturated steam-high temperature $\left(0.1\right.$ to $0.7 \mathrm{MPa}$ relating with 100 to $165^{\circ} \mathrm{C}$ during 5 to $60 \mathrm{~s}$ ). This is followed by an instant pressure drop towards a vacuum at about $5 \mathrm{kPa}$ at a rate $\Delta \mathrm{P} / \Delta \mathrm{t}$ higher than $0.5 \mathrm{MPa} \mathrm{s}^{-1}$. It simultaneously provokes an autovaporization of a part of the water and other volatile molecules within the product, and induces a swelling effect. An instant cooling of the products is capable to immediately stop 
thermal degradation. Depending on the severity of the treatment, the structure can be slightly or greatly modified. Also, the operating conditions can preserve or break the cell walls. DIC has been studied, developed, optimized and used at industrial scale. DIC ensues as specificunit operations of decontamination (Mounir \& Allaf, 2009), texturing (Kamal et al., 2008), and volatile compounds extraction from plants (Kristiawanet al., 2008). DIC also involves as a particular treatmentachieved in order to intensifyhot air drying, solvent extraction of non-volatile molecules such as flavonoids (Berka-Zougali et al., 2010), and other chemical or enzymatic reactions.

The technology was introduced to different sources of coffee beans prior to the roasting process. DIC treatment showed an interesting impact on expanding the bean microstructure (Kamal et al., 2008).

DIChas madeavery relevantextractionof essential oils, in spite of thehigh boiling pointof certain moleculesto about $220^{\circ} \mathrm{C}$. The most instructive studies were reported by(Kristiawanet al., 2008;Berka-Zugaliet al., 2010;Besombeset al., 2010), total extraction could be obtained in less than 4 min. Other research works proved that DIC used as a texturing pretreatment could dramatically intensify solvent extraction (Benamor \& Allaf, 2009).

Works regarding the detection and quantification of caffeinein complex media can be found in the literature(Belay et al., 2008). Among them are theultraviolet-visible spectroscopy and its derivatives (Belay, 2010), Liquid Chromatography (Pistos \& Stewart, 2004; Hywelet al., 2010), and gas chromatography (Espinoza-Perez et al., 2007). However, these works are focused on extraction and monitoring methods.

Finally, in terms of experimental design, we did not use in this study the one-factor-at-a-time approach, because it is time-consuming, expensive and doesn't allow evaluating the interaction effects among the various operating parameters. RSM (Response Surface Methodology) could overcome these difficulties by accounting the possible interaction effects between operating parametersin terms of various outputs. RSM has been successfully used to model and optimize biochemical and biotechnological processes related to food systems(Silva et al., 2007; Pompeuet al., 2009;Berkaet al., 2010).

\section{Materials and Methods}

\subsection{Reagents and chemicals}

All the materials used in this work are of analytical grade obtained fromFlukaChemie GmbH,Buchs, Switzerland.

\subsection{Plant material}

In this study, we used locally available Ethiopian green coffee beans. The first pretreatment involved grinding to 7-mm particles, whichwere then soaked in water bath at ambient temperature to reach predefined values of water content. Moisture content was measured using the oven method.Themeasurementswere triplicated and conducted on a $3 \mathrm{~g}$ of GCBs, placed in a thin layer glass capsule and dried in the oven at $105.5^{\circ} \mathrm{C}$ for $24 \mathrm{~h}$. The moisture content was determined between the initial raw material value of $11.00 \% \pm 0.2 \% \mathrm{db}$ (dry basis: $\mathrm{g} \mathrm{H}_{2} \mathrm{O} / 100 \mathrm{~g}$ dry matter)up to $35 \pm 0.2 \%$ dbfor soaked grains.

\subsubsection{Protocol of treatment}

In the present study, the treatment design was achieved as illustrated in Figure1.

\subsubsection{Instant controlled pressure drop DICtreatment and equipment}

DIC reactors have been presented in numerous articles (Besombeset al., 2010; Kamal and Allaf, 2011; Ben Amor et al., 2009).In the present work, the reactor used was a new developed version of DIC apparatus (Micro-DIC provided fromABCAR-DIC Process, La Rochelle, France) (Figure2). It is a $30 \mathrm{cc}$ processing vessel, a 7-liter vacuum tank connected with a water ring vacuum pump allowing the pressure to reach $5 \mathrm{kPa}$. A pneumatic valve ensures an "instant" connection between the vacuum tank and the processing vessel; it can open in less than 50 ms.Other valves control the flow of steam and compressed air within the processing vessel. Figure 3 shows the different stages of a DIC treatment.

Preliminary experiments were performed to define the range of various operating parameters such as saturated steam pressure $\mathrm{P}$, total thermal treatment time $t$ andGCBinitialwatercontent W.In a second stage, DIC extraction was carried out using a specific experimental design to identify and compare the effects of saturated steam pressure, process (heating) time and initial moisture content, chosen as operating parameters (or independent variables). The extracted product was collected as an emulsion of water and other compounds from the vacuum tank. The amount of caffeine present in this emulsion was quantified and defined as the "direct DIC extract" to be considered as a dependent variable (response) of the operation. 


\subsubsection{Solid - liquid extraction procedure}

Reflux water distillation-extraction was used as a solid-liquid extraction technique to extract caffeine from the untreated and DIC treated GCBs. A mixture of $1 \mathrm{~g}$ of concerned beans, distilled water $(20 \mathrm{ml})$ was heated inside a round button flask $(50 \mathrm{ml})$ using a thermostatic bath set at $97{ }^{\circ} \mathrm{C}$. The reflux distillation set-up was provided by magnetic agitation to ensure that the concentration of the extracted beans and the temperature of the solution were uniform within the flask. The crude extracts were filtered immediately after 20-min extraction using R-C membrane filter $0.45 \mu \mathrm{m}$ (Sartorius Stedim Biotech GmbH/Germany) and tested for caffeine quantification using HPLC. This amount of caffeine we defined as the " $20-\min -97^{\circ} \mathrm{C}$ aqueous extract" was considered as a dependent variable (response) of the operation.

\subsubsection{Instrumentation and chromatographic conditions}

A reversed phase HPLC system (Agilent Instruments, 1100 series, Massy, France) was used. The Chromatographic system consisted of a vacuum degasser on line with three solvent delivery pumps linked to a thermostatted column compartment via auto-sampler. The detection was carried out using a diode array UV detector $(200-400 \mathrm{~nm})$. Data was collected and processed using HPLCChemstation software program (Agilent, version B.04.01, Massy, France).

Caffeine crude extracts were separated on a Pursuit XRs Ultra C18 $(2.8 \mu \mathrm{m}), 150 \times 2 \mathrm{~mm}$ (Varian - Agilent). The mobile phase A was a mixture of water/acetic acid and the mobile phase $\mathrm{B}$ was acetonitrile. Both of them were filtered through a $0.45 \mu \mathrm{m}$ membrane filters. The elution program is outlined in table 1 . The flow-rate was set at 0.4 $\mathrm{ml} / \mathrm{min}$ and the column compartment was kept at a controlled temperature of $50 \pm 0.5{ }^{\circ} \mathrm{C}$ during all runs. The absolute pressure was $0.341 \mathrm{MPaand}$ the capillary voltage was $3 \mathrm{kV}$.

Quantification was carried out using calibration curve obtained with standard caffeine at $272 \mathrm{~nm}$. For the spectrophotometric procedure, a standard curve was determined over y range of $(0.05-9) \mu \mathrm{g} / \mathrm{ml}$ as analyte concentrationversus $\mathrm{x}$ as the experimental measured area, with $\mathrm{R}^{2}=0.99994$ showing good adherence to Beer's Law:

$$
y=-5 * 10^{-29} x^{4}+7 * 10^{-21} x^{8}+3 * 10^{-14} x^{2}+4 * 10^{-7} x-7 * 10^{-4}
$$

The experimental results were mentioned as average \pm standard deviation (SD) of three measurements.

\subsubsection{Drying process}

AfterDICand aqueous extraction of GCBs, a conventional drying was achieved on a static-tray type with air flux at initial temperature of $40 \pm 1{ }^{\circ} \mathrm{C}$, velocity of $1 \pm 0.2 \mathrm{~m} \mathrm{~s}^{-1}$, and initial humidity of $265 \mathrm{~Pa}$. A precision balance (AdventureOhaus Europe GmbH, Greifensee, Switzerland) with an accuracy of $0.1 \mathrm{mg}$ was used for weighing the untreated and DIC treated GCBssamples. Before beginning the experiments, the dryer system was started in order to achieve desirable steady state conditions. The samples weight were measured after sequential drying intervals and the drying continued until no further changes in the sample mass were observed, e.g. to the final moisture content of about $5 \% \mathrm{db}$ which was then taken as the equilibrium moisture content.

\section{Fundamentals}

\subsection{High temperaturevolatile extraction}

Some authors noted that roasting of GCBs is usually linked to a slight lose of caffeine by evaporation or sublimation. Such phenomenon never has been considered as complete heat extraction process.Fundamental approach carried out by Mounir and Allaf, (2009) assumes that heat transferredinto theplant considered as porous material mainly assures a phase change (liquid/vapor) with a partial pressure strictly depending on the temperature. The mass transport of volatile molecules from the grain surface to the surrounding environmentcan be intensified. Thatlet the internal heat and mass transfers become the limiting process.

The internal heat transfer is mainly processed by a similar conduction phenomenon. The porous structureincluding air,water and volatile molecules,allows vaporization-condensation phenomena inside the product holes. The global phenomenon is a conduction-type transfer where the gradient of temperature is conducted as the driving force with a higher value of effective conductivity. The main part of such heat flow is used to evaporate water and volatile compounds within the product holes: 


$$
-\lambda_{e f \gamma} \vec{V} \cdot \vec{V} T+s_{a z g} M_{c} L_{e} \frac{\partial}{\partial t}\left[\frac{p_{0}}{k T}\right]=0
$$

The internal transfer of volatile compoundsis assumed to be negligible under a liquid phase, and achieved as puregas phase diffusion. It can be revealed by a Fick-type's law with the gradient of the partial pressure per temperature of each volatile compound as driving force. (Allaf, 1982):

$$
\frac{P_{\sigma} / T}{\rho_{g}}\left(\vec{v}_{\theta}-\vec{v}_{g}\right)=-D_{e s f} \overrightarrow{\vec{v}} \frac{\overrightarrow{P_{\sigma}} / T}{\rho_{g}}
$$

where $\mathrm{D}_{\text {eff }}$ is the effective mass diffusivity.

3.1.1 Paradox of coupled internal heat and gas diffusion transfers

The partial pressures of water and other volatile compounds inside the holes of the plant considered as porous material closely depend on the temperature through the thermodynamic liquid/gas equilibrium of the molecule mixture. By neglecting the possible shrinkage phenomena, one can assume:

$$
\left(p_{\sigma / T}\right) \vec{v}_{v}=-D_{\theta f f} \vec{V}\left(p_{c / T}\right)
$$

The gradient of $\beta_{k} / T$ is then the driving force ofgasdiffusion (which is controlled by) and the transfer of heat to change the liquid into gas phase within the porous material,can be coupled to become, with one $\mathrm{x}$ dimension, as:

$$
\begin{aligned}
& -\lambda \frac{\partial^{2} T}{\partial x^{2}}+a_{a v g} M_{0} E_{\theta} \frac{\partial\left[\frac{p_{c}}{\partial T} .\right.}{\partial t}=0 \\
& \left(v_{v} / V_{T}\right) v_{\theta}=-D_{\theta f f}\left(\frac{\left.\partial v_{v} v_{T}\right)}{\partial x}\right)
\end{aligned}
$$

However, as $\left(v_{c} / T\right)$ is as higher as the temperature is higher,

$$
\frac{\partial\left(p_{\sigma} / q^{\prime}\right)}{\partial T}>0
$$

the gradient of mass transfer is then directed from the surface to the sample core; the result is a paradoxical situation implying a motion completely opposite to that required for the sought extraction operation. In the usual heat extraction of volatile molecule from plant oils, the process is achieved by slow "front progression" kinetics.

\subsubsection{Specificity of the DIC treatment}

Depending on thehigh temperature level of DIC, the total pressure of the mixture vapor and volatile molecules in the porous material is, just after the pressure drops, much higher than the external vacuum pressure. Therefore, whatever the structure of the porous plant, the mass transfer operation within this porous matrix has to be performed from the core towards the surrounding medium through the gradient of the total pressures (Darcy-type law): 


$$
P_{0} v_{o}=-\frac{K}{v_{0}} \frac{\partial P}{\partial x}
$$

By considering mass balance and continuity laws, and by integrating between the hole (whose radius $R_{o}$ ) and the external radius $R_{s}$ of the spherical shape, Allafet al., 2011 calculated the part $m_{m}$ of vapor mixture removed as:

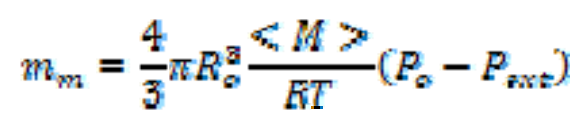

Usually, the time $t_{v}$ of the final vacuum DIC stage just after pressure drops is defined to allow the mixture vapor to be transported towards the surrounding medium and then collected.

DICis fundamentally relevant to remedy the disadvantages of the paradoxical stage and can greatly intensify the thermal extraction of volatile compounds.

\subsection{Fundamentals of hot air drying kinetics}

When external heat and mass transfers are not the limiting phenomena of the operation kinetics thanks to adequate air flow temperature and velocity, only internal transfers are considered as controlling and limiting the whole operation (Al-Haddad et al.; 2008). Mounir and Allaf (2009) havemodeled such dehydration kinetics, in the case of porous medium by couplingthe internal transfer processes with an initial superficial drying assumed to be the limiting process during the first part of the operation.

As usually internal mass transfer in vegetables is much slower than conduction heat transfer within the product, the drying kinetics is claimed as controlled bywater diffusion within the solid structure. GCBs can be assumed as isotropic structure in terms of water flow within the material; by assuming a constant temperature and homogeneous structure, different 1-D mathematical solutions may be proposed, depending on the boundary conditions (Pakowski and Mujumdar, 2006; Crank, 1975); limited to the first term approximation, a straight-line equation may be obtained through the logarithmic transformation of the adimensional water content dry basis:

$$
Y=L N\left(\frac{W_{w}-W_{\sigma}}{W_{\infty}-W^{2}}\right)=k t+c t \theta
$$

GCBcan be assumed to be spherical shape with $d_{p}$ as radius. The effective diffusivity is:

$$
D_{e f f}=\frac{k d_{p}^{2}}{\pi^{2}}
$$

The experimental data used to determine the effective diffusivity $\mathrm{D}_{\text {eff }}$ from the Fick's model exclude the ones concerning the points close to $\mathrm{t}=0$; the extrapolation of the model thus obtained leads to evaluate $\mathrm{W}_{\mathrm{o}}$ as, generally, distinct from the initial humidity content $\mathrm{W}_{\mathrm{i}}$. The difference at the starting point between $\mathrm{W}_{\mathrm{i}}$ and $\mathrm{W}_{\mathrm{o}}$ revealsthe starting accessibility $\delta W_{s}$, which is the superficial water capable to be quickly removed from the surface, independently from diffusion process.

\section{Statistical and Experimental Design Protocol}

Several authors (Benoistet al., 1994; Kamal et al., 2008) developed RSM (response surface methodology) in order to identify the effects of each factor (independent variables or operating parameters) and target the optimal treatment conditions with the possibility of maximizing the information and obtaining the most relevant responses from the lowest number of trials. In the present work, this experimental design was defined after some preliminary trials to test the behavior of the plant (structure expansion, thermal degradation etc.) versus the operating parameters. The results of these preliminary experiments allowed us to select only three factors that seemed to have a significant influence in our case. These were saturated steam pressure $\mathrm{P}$, initial water content $\mathrm{W}$, and total thermal processing time t. They ranged from 0.1 to $0.6 \mathrm{MPa}, 11$ to $35 \% \mathrm{db}$, and 16 to $84 \mathrm{~s}$, respectively (Table 1 ). Other parameters, such as the final pressure in the vacuum tank and the pressure drop rate were kept constant. A full central composite design with the three independent variables and seven replicates at the central point, i.e. a total of 21 trials, was employed for evaluating the effect of steam DIC treatment on GCBsdecaffeination and 
drying kinetics. The trials were run randomly to minimize the effects of an unexpected variability of responses due to unrelated and uncontrolled factors.

The statistical analysis of the results was carried out using the analysis design procedure of Statgraphics Plus software for Windows (1995, version 5.1, Levallois-Perret, France). Variance (ANOVA) was performed to determine significant differences between independent variables $(\mathrm{P} \leq 0.05)$. The effects of the independent variables or operating parameters on each parameter response were revealed under Pareto chart, which is usually very effective when introduced to describe a phenomenon in which $95 \%$ of the variation observed in experimental processes can be explained by a mere $5 \%$ of the causes of that variation.

Pareto chartis introduced together with the main trends, response surface, empirical model coefficients and $\mathrm{R}^{2}$. The response parameter (dependent variable $\mathrm{Y}$ ) is expressed through a second-order polynomial empirical model of independent variables:

$$
Y=\beta_{0}+\sum_{i=1}^{n} \beta_{i} x_{i}+\sum_{i=1}^{n} \beta_{i t} x_{i}^{2}+\sum_{i=1}^{n} \beta_{i} x_{i} x_{i}+\varepsilon
$$

where $\beta_{g}, \beta_{i}, \beta_{i:}$ and $\beta_{t,}$ are the regression coefficients, $x_{i}$ the independent variables, sthe random error, $\mathrm{i}$ and $\mathrm{j}$ the indices of the factors. Response Surface Methodology can be used to optimize the operating parameters by coupling various studied responses. The dependent response variables were the amount of DIC-direct caffeine extract"DIC-DEC", the amount of 20 -min- $97^{\circ} \mathrm{C}$ aqueous caffeine extract "ACE", the total decaffeination ratio "TDR", and the direct decaffeination ratio "DDR", as well as the drying kinetic parameters such as the drying time to reach a water content level of $5 \% \mathrm{db}$ " $\mathrm{t}_{5 \%}$ ", the effective diffusivity " $\mathrm{D}_{\text {eff }}$ " and the starting accessibility " $\mathrm{W}_{\mathrm{s}}$ ".

\section{Results and Discussion}

\subsection{Extraction processes}

The process of DIC-direct-extraction of caffeine should involve the autovaporization of volatile compounds. Thisphenomenon strictly appears when the pressure drops instantaneously. Furthermore, the increase in porosity and the appearance of holes due to the possible expansion of the matter allow water and other solvents to easily diffuse within the new structure; rupture of cell walls can occur at high severity DIC treatment.

The liquid resulted from the condensation of the vapor expelled into the vacuum tank by dropping the DIC pressure was clear, homogeneous, with a pleasant coffee odor. Caffeine present in this liquid was quantified and reported to the quantity of dry treated GCBs. The $20-\min -97^{\circ} \mathrm{Caqueous}$ caffeine extracted from the untreated and DIC-treated GCBs was measured and quantified reported to dry matter.DIC treatment was designed to assess and identify the efficacy of the two operations by quantifying the amount of DIC-Extract Caffeine (DIC-DEC) and GCBAqueous Extract Caffeine (AEC).

\subsubsection{Direct extraction of caffeine by DIC treatment}

The DIC-direct extract caffeine expelled in the vacuum tank had a concentration in the condensed water between 0.005 and $0.133 \% \mathrm{db}$.

RSM analysis for direct DIC-DEC revealed that the effects of the processing time ( $\mathrm{t}$ ) and the saturated steam pressure $(\mathrm{P})$ reflecting the processing temperature were both significant; whereas the initial water content $(\mathrm{W})$ had a lower impact (Figure 4a). It is worth noting that the higher the saturated steam pressure $(\mathrm{P})$ and the processing time $(\mathrm{t})$, the higher the DIC-DECvalue (Figure4b).

RSM analysis generated a second order polynomial model, and estimated response surfaces shown in (Figure4c).The regression coefficients of the model for caffeine directly expelled by DIC were obtained by multiple linear regressions. The polynomial empirical modelcould be estimated and expressed with $\mathrm{R}^{2}=0.788952$ as the following:

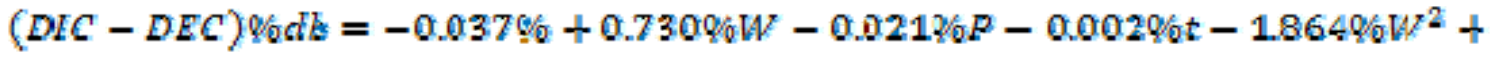

$$
\begin{aligned}
& 0.30 \% W_{0} W F+0.001 \% 6 V t-0.105 \% E^{2}+0.003 \% E t+1.610^{-8} \%_{0} t^{2}
\end{aligned}
$$

The highest direct caffeine extraction DIC-DEC was calculated as $0.1622 \% \mathrm{db}$, at optimal conditions of $0.6 \mathrm{MPa}$ saturated steam pressure, $27.53 \% \mathrm{db}$ water content and $84 \mathrm{~s}$ thermal treatment time. This was higher than the content of lightly roasted coffee $(0.06 \%$ as was reported by Hecimovic et al., (2011). This increase can be explained by the expulsion of some volatile compounds thanks to the gradient of the total pressure between GCB 
core and the surrounding vacuum medium. Indeed, in a similar situation even with essential oil extraction, Al-Haddad et al., (2007) and Besombeset al., (2010) indicated that Darcy-similar process could effectively remedy the paradoxical stage.

The values of DIC-DEC were systematically underestimated, because a certain amount of caffeine should have been retained on the vacuum tank wall and vacuum pump.However, the results proved the ability of DIC to quickly remove a certain amount of caffeine from GCBs, with low energy consumption and water vapor as proved byMounir and Allaf (2008).

\subsubsection{Aqueous extraction of caffeine}

20-min- $97{ }^{\circ} \mathrm{C}$ aqueous extraction was operated on untreated and DIC-treated GCBs. Each experiment treatment was carried out in triplicate and the average of aqueous extract caffeine "AEC" expressed in \%db was taken as the response.

RSM analysis for aqueous extract caffeine AEC revealed that the effects of the saturated steam pressure (P) reflecting the processing temperature, and the initial water content $(\mathrm{W})$ were the most significantDIC operating parameters; whereas the processing time (t) had a too low impact (Figure5a).

In the considered ranges, the higher the values of water content $(\mathrm{W})$, saturated steam pressure $(\mathrm{P})$, and processing time ( $\mathrm{t}$ ), the lower the aqueous extract caffeine AEC (Figure 5b).However, at high P level (about 0.6 MPa) and at high W level (about 35\% db), AEC kept constant, independently of W and P, respectively (Figure 5c).

The regression coefficients of the model for caffeine directly expelled by DIC were obtained by multiple linear regressions. The polynomial empirical model could be estimated and expressed with $\mathrm{R}^{2}=0.71$ as the following:

\section{$A E C=\left(3.670-7.197 W-4.925 P-0.007 t+2.388 W^{2}+12.642 W P-0.003 W t\right.$ $\left.+0.946 P^{2}+0.005 P t+10510^{-8} t^{2}\right) \%$}

Although increasing the DIC processing pressure is correlated with increasing the steam temperature, the dissolution and extraction of caffeine in the aqueous solution seemed to decrease with increasing DIC temperature, possibly because a higher retention of caffeine. The highest theoretical value of $\mathrm{AEC}$ was obtained at $\mathrm{P}=0.1 \mathrm{MPa}$, $\mathrm{W}=11.0 \% \mathrm{db}$, and $\mathrm{t}=35 \mathrm{~s}$; its optimized value was calculated as $2.35 \% \mathrm{db}$.

\subsection{Decaffeination process}

The new decaffeination process was triggered as two stages issued from:

a. DIC direct caffeine extraction; the crude directly extract was collected in the extract container of the DIC apparatus,

b. Aqueous caffeine extraction.

The first stage allows a part of caffeine to be directly expelled towards the vacuum tank once the DIC pressure abruptly dropped, while the second stage was greatly intensified thanks to the DIC expanded structure. Indeed, by expanding GCBs, DIC treatment could dramatically increase water diffusion and solvation.

The average amount of total extracted caffeine in the first experimental design could then reach up to $1.891 \pm 0.04 \mathrm{~g}$ of caffeine $/ 100 \mathrm{~g}$ dry GCBs, which represented a decaffeination ratio up to $80 \%$, while it was only $1.3640 \pm 0.04$ $\mathrm{g} / 100 \mathrm{~g}$ dry matter representing a decaffeination ratio of $58 \%$ when the aqueous extraction was achieved with untreated GCBs. Research works on DIC treatment of various plants highlighted similar behavior revealing greater availability of compounds to be extracted normally because of expansion and possible broken cell walls.

Statistical analyses of total decaffeination ratio TDRillustrated in (Figure 6-a,b,c),showed the effects of DIC operating parameters such as the saturated steam pressure (P), the initial water content $(\mathrm{W})$ of GCBs, and the DIC processing time $t$ on total decaffeination ratio TDR. $\mathrm{P}$ and $\mathrm{W}$ were the most significant variables with a negative impact; that means that TDR decreased with increasing $\mathrm{P}$ and W.TDR were revealed through the following polynomial expression established with $\mathrm{R}^{2}=0.70$ :$$
T D R=\left(190.241-338.641 W-259.029 P-0.450 t+27.408 W^{2}+678.102 W P\right.
$$$$
\left.-0.101 \% W t+44.036 P^{2}+0.416 P t+0.0014 t^{2}\right) \%
$$

The optimalTDRcorresponded to a complete decaffeination, which was estimated at $99.5 \%$ at optimized DIC conditions of $\mathrm{W}=11.00 \% \mathrm{db}, \mathrm{P}=0.1 \mathrm{MPa}$, and $\mathrm{t}=35 \mathrm{~s}$. 
Moreover, it worth to be noted that, as expected, despite itslow level, the direct contribution ofDICtodecaffeinationby the expulsionof caffeinetowards the vacuum tank should be very important because of the short operation time, the high concentration level, and the low energy consumption reported to the amount of extract.

From experimental data, it was possible to establish the response analysis as shown in (Figure7-a,b,c), and an empirical model of the DDR versus the DIC processing parameters. The $\mathbb{R}^{2}$ value $\left(\mathbb{R}^{2}=0.789\right)$ directly proved that the DIC treatment was a relevant extraction process with caffeine:

$$
\begin{aligned}
D D R & =\left(1.926+38.235 W-1.105 P-0.104 t-97.635 W^{2}+16.064 W P\right. \\
& \left.+0.070 W t-5.487 P^{2}+0.167 P t+0.001 t^{2}\right) \%
\end{aligned}
$$

The highest value of DDRof $8.5 \%$ could be obtained with initial water content $\mathrm{W}=27.5 \% \mathrm{db}$, at a saturated steam pressure $\mathrm{P}=0.6 \mathrm{MPa}$ during processing time $\mathrm{t}=84 \mathrm{~s}$.

\subsection{Drying kinetics}

After the decaffeination process, and just before roasting, GCBs have to be dried. The impact of DIC on drying kinetics should be correlated with DIC-expansion. At first, it was evident to note that the drying time needed to let GCBs reach moisture of 5\% dbwas much lower with DIC-treated grains than raw material (Table 2).

In our case, the lowest value of $\mathrm{t}_{5} \%$ was obtained with the following values of DIC operating parameters: $\mathrm{P}=0.6$ $\mathrm{MPa}, \mathrm{W}=23 \% \mathrm{db}$ and $\mathrm{t}=50 \mathrm{~s}$ with $\mathrm{t}_{5 \%}=60 \mathrm{~min}$ instead of $528 \mathrm{~min}$ for untreated raw material.

On the other hand, response surface method RSM analysis confirmed that DIC processing pressure $\mathrm{P}$ and time $\mathrm{t}$ had negative linear effects on $t_{5 \%}$ that means the higher the DIC operating parameters $\mathrm{P}$ and $\mathrm{t}$, the more effective the drying kinetics. (Figure 8-a,b,c) displays the effects, while the empirical mathematical model was established with $\mathrm{R}^{2}=68.636$ percent as following:

$$
\begin{gathered}
t_{\mathrm{B} \%}=204.006+980.295 \mathrm{~W}+501.661 P-5.218 t-687.756 \mathrm{~W}^{2}-1655.62 W P \\
-6.107 \mathrm{~W} t-218.591 P^{2}-4.034 P t+0.057 t^{2}
\end{gathered}
$$

\subsubsection{Drying model}

In the present work, the mathematical diffusion-drying model coupled with the initial surface interaction was fitted to experimental data using non-linear regression analysis techniques. The experimental data of moisture (\% dry basis) versus time were used in order to assess a suitable form of the drying curve for GCBs. They allowed determining the starting accessibility $\mathrm{W}_{\mathrm{s}}$ and the effective diffusivity $\mathrm{D}_{\text {eff }}$ adapted to each drying curve of untreated and DIC treated GCBs. The statistical treatment of these results revealed the remarkable improvement in the starting accessibility and the moisture diffusivity that could be achieved when coffee beans are pre-treated by DIC prior to drying. In the present case of DIC treated samples, they ranged from 5 to $17.8 \mathrm{~g} / 100 \mathrm{~g} \mathrm{db}$ and from 5.4 to $28.410^{-10} \mathrm{~m}^{2} \mathrm{~s}^{-1}$, respectively; as against $0.8 \mathrm{~g} / 100 \mathrm{~g} \mathrm{db}$ and $1.310-10 \mathrm{~m}^{2} \mathrm{~s}^{-1}$, respectively for the raw material. These last values correlate with those reported for coffee cherries by Sfredoet al., (2005); Hernandez-Diaz et al., (2008) of an effective moisture diffusivity between $110^{-11}$ and $110^{-10} \mathrm{~m}^{2} \mathrm{~s}^{-1}$ at $45^{\circ} \mathrm{C}$ and between $310^{-11}$ and 3 $10^{-10} \mathrm{~m}^{2} \mathrm{~s}^{-1}$ at $60^{\circ} \mathrm{C}$.

DIC textured beans with increased pore size and greater exchange surface enhance the powerful raise of drying kinetics through effective responses. The results are in agreement with other DIC experiments carried out on various food products (Albitar et al., 2011).

It was then possible to establish the response surface analysis (Figure9-a,b,c and Figure 10-a,b,c), and the empirical mathematical models of the effective diffusivity $\mathrm{D}_{\text {eff }}$ and the starting accessibility $8 \mathrm{~W}_{s}$ versus the DIC processing parameters $\mathrm{P}, \mathrm{t}$ and $\mathrm{W}$. The regression coefficients of the models were obtained by the multiple linear regressions, and the polynomial equations estimated are expressed as the following:

$$
\begin{gathered}
D_{\text {eff }}=13.6381-24.103 W-34.969 P-0.226 t-37.860 W^{2}+95.280 W P+0.423 W t \\
+10.77 C P^{2}+0.303 P t+0.001 t^{2}
\end{gathered}
$$




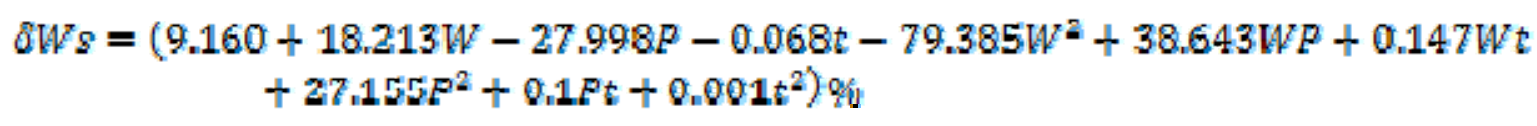

with $\mathrm{R}^{2}$ values 0.72 and 0.55 , respectively. Though these $\mathrm{R}^{2}$ values of $\mathrm{D}_{\text {eff }}$ and $\delta W_{s}$ reveal that these equations reflect a general trend rather than a precise relationship, but all of these relations shows the great impact of DIC pretreatment in the improvement of the drying kinetics; possibly through the porous structure.

From these second order polynomial models generated by response surface analysis, optimal drying conditions of GCBs were obtained using the predictive equations generated by RSM:

Thehighest valuesof $\mathrm{D}_{\text {eff }}$ at $1.999410^{-9} \mathrm{~m}^{2} \mathrm{~s}^{-1}$ and $\delta W_{s}$ at $13.901 \%$ were obtained at the same DIC operating parameters $\mathrm{P}=0.6 \mathrm{MPa}$ and $\mathrm{t}=84 \mathrm{~s}$, while the water contents slightly differed to be $\mathrm{W}=33.5 \% \mathrm{db}$ and $25.6 \% \mathrm{db}$, respectively.

Finally, it worth to note that the same optimal DIC treatment parameters were defined for DDR/Total extracted caffeine. General correlations(Figure 11) were recognized between $\mathrm{D}_{\text {eff }}$, andDDR/Total extracted caffeine with $79.5 \%$ as correlation factor. Both of these response parameters should be directly linked to porosity and porous structure.

\section{Conclusions}

The results obtained throughout this work concludethata new decaffeination process could be defined and applied on green coffee beans (GCBs). It is a two-step operation of Détente InstantanéeContrôléeDIC (French, for instant controlled pressure-drop)and an aqueous extraction, normally followed by a drying step, prior to storing and roasting. The first stage of thermo-mechanical process DIC leaded to an expulsion of a part of caffeine possibly by autovaporization; it is the "direct decaffeination" step. DIC treatment can also allow the structure to be expanded and solvent extraction to be dramatically intensified. A "20-min- $97{ }^{\circ} \mathrm{C}$ aqueous extraction" was defined as the second step of this solvent-free, environmentally decaffeination. In the present work, both operations of decaffeination and drying were achieved on Ethiopian green coffee beans. The highest value of the direct decaffeination ratio DDRcould be $8.5 \%$ of total caffeine content and corresponded to a DIC saturated steam pressure $\mathrm{P}=0.6 \mathrm{MPa}$, for a DIC processing time $\mathrm{t}=84 \mathrm{~s}$ with an initial moisture content $\mathrm{W}=27.5 \%$. Untreated and DIC-treated GCBs were then submerged for $20 \mathrm{~min}$ in water bath at $97{ }^{\circ} \mathrm{C}$. Thus, a total decaffeination ratio TDRwas obtained.With optimized DIC treated GCBs of $\mathrm{W}=11.00 \% \mathrm{db}, \mathrm{P}=0.1 \mathrm{MPa}$, and $\mathrm{t}=35 \mathrm{~s}$, TDRcorresponded to a complete decaffeination, which was estimated at $99.5 \%$ while only $58 \%$ could be extracted from the untreated raw materials.

Using the classical diffusion coupled with surface interaction model of hot-air drying kinetics, DIC expansion dramatically improved the drying kinetic parameters. Thus, the effective diffusivity $D_{\text {eff }}$ and the starting accessibility $\delta W_{s}$ increased $3780 \%$ and $1537 \%$, respectively. Drying time needed to reach $5 \%$ db became 60 min instead of $528 \mathrm{~min}$ for untreated raw material.

From a technological point of view, thisnew route for coffee decaffeination is very promising because of various drawbacks related to the traditional decaffeination processes.

\section{Acknowledgements}

The authors would like to acknowledge the financial support from CPER/EU-FEDER. The authors wish to extend their heartfelt gratitude to Mr. Laurent Lefevre, from ABCAR-DIC Process for having contributed to the scaling up DIC treatments and for having provided them with the raw material thus contributing to perform these tests.

\section{References}

Albitar, N., Mounir, S., Besombes, C., \& Allaf, K. (2011). Improving the Drying of Onion Using the Instant Controlled Pressure Drop Technology. Journal of Drying Technology, 29 (9), 993-1001. http://dx.doi.org/10.1080/07373937.2010.507912

Allaf, K., Besombes, C., Berka- Zougali, B. Kristiawan, M., \& Sobolik, V. (2011). Instant controlled pressure drop (DIC) technology in plant extraction processes. In: "Enhancing Extraction Processes in the Food Industry", Series on "Contemporary Food Engineering", Taylor \& Francis-CRC Press, London (UK), ISBN: 9781439845936.

Allaf, K., Maache-Rezzoug, Z., Louka, N., Debs-Louka, E., Abraham, G., Rezzoug, S. A., et al., (1998). French patent WO/1999/042003. 
Belay, A. (2010). Measurement of integrated absorption cross-section, oscillator strength and number density of caffeine in coffee beans by integrated absorption coefficient technique. Food Chemistry, 121 (2), 585-590. http://dx.doi.org/10.1016/j.foodchem.2009.12.052

Belay, A., Ture, K., Redi, M., \& Asfaw, A. (2008) Measurement of caffeine in coffee beans with UV/VIS spectrometer. Food Chemistry, 108 (1), 310-315. http://dx.doi.org/10.1016/j.foodchem.2007.10.024

BenAmor, B., \& Allaf, K. (2009). Impact of texturing using instant pressure drop treatment prior to solvent extraction of anthocyanins from Malaysian Roselle (Hibiscus sabdariffa). Food Chemistry, 115 (3), 820-825. http://dx.doi.org/10.1016/j.foodchem.2008.12.094

Benoist, D., Tourbier, Y., \& Germain-Tourbier, S. (1994). Plans d'expériences, Construction etAnalyse, p. 208 Lavoisier Tec \& Doc, London, UK.

Berka-Zougali, B., Hassani, A., Besombes, C., \& Allaf, K. (2010). Extraction of essential oils from Algerian myrtle leaves using instant controlled pressure drop technology. Journal of Chromatography A, 1217, 6134-6142. http://dx.doi.org/10.1016/j.chroma.2010.07.080

Besombes, C., Berka-Zougali, B., \& Allaf, K. (2010). Instant controlled pressure drop extraction of lavandin essential oils: Fundamentals and experimental studies. Journal of Chromatography A, 1217, 6807-6815. http://dx.doi.org/10.1016/j.chroma.2010.08.050

Clarke, R. J. (2003). Coffee decaffeination. In Encyclopedia of Food Sciences and Nutrition, (pp.1506-1511). Elsevier Science Ltd. http://dx.doi.org/10.1016/B0-12-227055-X/00272-8

Crank, J. (1975).The Mathematics of Diffusion. (2nd ed., ISBN-10: 0198533446, ISBN-13: 978-0198533443). Clarendon Press, Oxford.

Cuong, N. T., Tai, T. B., Ha, V. T. T., \& Nguyen, M. T. (2010).Thermomechanical parameters of caffeine, theophylline, and xanthine. Journal of chemical thermodynamics, 42(4), 437-440. http://dx.doi.org/10.1016/j.jct.2009.10.006

De Maria, C., Trugo, L. C., Aquino Neto, F. R., Moreira, R. F. A., \& Alviano, C. S. (1996). Composition of green coffee water-soluble fractions and identification of volatiles formed during roasting. Food Chemistry, 55 (3), 203-207. http://dx.doi.org/10.1016/0308-8146(95)00104-2

De Maria, C., Trugo, L. C., Moreira, R. F. A., \& Werneck, C. C. (1994). Composition of green coffee fractions and their contribution to the volatile profile formed during roasting. Food Chemistry, 50 (2), 141-145. http://dx.doi.org/10.1016/0308-8146(94)90111-2

Emelyanenko, V. N., \& Verevkin, S. P. (2008). Thermodynamic properties of caffeine: Reconciliation of available experimental data. Journal of chemical thermodynamics, 40(12), 1661-1665. http://dx.doi.org/10.1016/j.jct.2008.07.002

Espinoza-Perez, J. D., Vargas, A., Robles-Olvera, V. J., Rodriguez-Jimenez, G. C., \& Garcia-Alvarado, M. A. (2007). Mathematical modeling of caffeine kinetic during solid-liquid extraction of coffee beans. Journal of Food Engineering, 81(1), 72-78.

Franca, A. S., Mendonça, J. C. F., \& Oliveira, S. D. (2005).Composition of green and roasted coffees of different cup qualities. LWT - Food Science and Technology, 38 (7), 709-715.

Fujioka, K., \& Shibamoto, T. (2008). Chlorogenic acid and caffeine contents in various commercial brewed coffees. Food Chemistry, 106 (1), 217-221. http://dx.doi.org/10.1016/j.foodchem.2007.05.091

Glade, M. J. (2010). Caffeine not just a stimulant.Nutrition, 26 (10), 932-938. http://dx.doi.org/10.1016/j.nut.2010.08.004

Gokulakrishnan, S., Chandraraj, K., \& Gummadi, S. N. (2005).Microbial and enzymatic methods for the removal of caffeine. Enzyme and Microbial Technology, 37(2), 225-232. http://dx.doi.org/10.1016/j.enzmictec.2005.03.004

Griesse, U. J., Szelagiewicz, M., Hofmeier, U., Pitt, C., \& Cianferani, S. (1999). Vapor Pressure and Heat of Sublimation of Crystal Polymorphs. Journal of Thermal Analysis and Calorimetry, 57(1), 45-60. http://dx.doi.org/10.1023/A:1010188923713

Hernandez-Diaz, W. N., Ruiz-Lopez, I. I., Salgado-Cervantes, M. A., Rodríguez-Jimenes, G. C. \& García-Alvarado, M. A. (2008). Modeling heat and mass transfer during drying of green coffee beans using 
prolate spheroidal geometry. Journal of Food Engineering, 86(1), 1-9. http://dx.doi.org/10.1016/j.jfoodeng.2007.08.025

Hywel, D. W., David, A. B., Robert, W., Ian, J.H., \& Colin, D. M. (2010). A liquid chromatography method for quantifying caffeine dissolution from pharmaceutical formulations into colloidal, fat-rich media. Journal of Chromatography B, 878 (21), 1739-1745. http://dx.doi.org/10.1016/j.jchromb.2010.04.032

Içen, H., \& Guru, M. (2009). Extraction of caffeine from tea stalk and fiber wastes using supercritical carbon dioxide. The Journal of Supercritical Fluids, 50(3), 225-228. http://dx.doi.org/10.1016/j.supflu.2009.06.014

James, A. G., Carol, N. B., \& Allan, G. (2006). Coffee, diabetes, and weight control. American Journal of Clinical Nutrition, 84 (4), 682-693.

Kamal, I. M., Sobolik, V., Kristiawan, M., Mounir, S. M., \& Allaf, K. (2008). Structure expansion of green coffee beans using instantaneous controlled pressure drop process. Innovative Food Science \& Emerging Technologies, 9 (4), 534-541. http://dx.doi.org/10.1016/j.ifset.2008.01.004

Kristiawan, M., Sobolik, V., \& Allaf, K. (2008). Isolation of Indonesian cananga oil using multi-cycle pressure drop process. J. Chromatography. A 1192 (2).306-18. http://dx.doi.org/10.1016/j.cep.2007.08.011

Kristiawan, M., Sobolik, V., Al-Haddad, M., \& Allaf, K. (2008). Effect of pressure-drop rate on the isolation of cananga oil using instantaneous controlled pressure-drop process. Chemical Engineering and Processing: Process Intensification, 47(1), 66-75.

Ky, L., Louarn, J., Dussert, S., Guyot, B., Hamon, S., \& Noirot, M. (2001). Caffeine trigonelline, chlorogenic acids and sucrose diversity in wild coffeaarabica L. and C. canephora P. accessions. Food Chemistry, 5(2), 223-230. http://dx.doi.org/10.1016/S0308-8146(01)00204-7

Maeso, N., Dell Castillo, C., Cornejo, L., García-Acicollar, M., Alguacil, L. F. \&Barbas, C. (2006). Capillary electrophoresis for caffeine and pyroglutamate determination in coffees: Study of the in vivo effect on learning and locomotor activity in mice. Journal of Pharmaceutical and Biomedical Analysis, 41(4), 1095-1100. http://dx.doi.org/10.1016/j.jpba.2006.01.062

Mounir, S. \& Allaf, K. (2008). Three-Stage Spray Drying: New Process involving Instant Controlled Pressure Drop. Drying Technology, 26(4), 452-463.

Mounir, S. \& Allaf. K. (2009). Study and modeling of dehydration and rehydration kinetics within porous medium. In: Proceedings of European Drying Conference AFSIA, Lyon, France. http://dx.doi.org/10.1080/07373930801929334

Pakowski, Z. \& Mujumdar, A. S. (2006). Basic process calculations and simulations in drying.In Hanbook of industrial drying; 3rd ed. CRC Taylor \& Francis Group Press, ISBN1574446681, 9781574446685.

Parliament, T. H. \& Stahl, H. B. (1995). What makes the coffee smell so good? Chemtech, 25(8), 38-47.

Pistos. C. \& Stewart, J. T. (2004). Assay for the simultaneous determination of acetaminophen-caffeine-butalbital in human serum using a monolithic column., Journal of Pharmaceutical and Biomedical Analysis, 36 (4), 737-741. http://dx.doi.org/10.1016/j.jpba.2004.07.042

Pompeu, D. R., Silva, E. M. \& Rogez, H. (2009). Optimisation of the solvent extraction of phenolic antioxidants from fruits of Euterpeoleracea using Response Surface Methodology. BioresourTechnol, 100(23), 6076-6082. http://dx.doi.org/10.1016/j.biortech.2009.03.083

Rodrigues, C. I., Marta, L., Maia, R., Miranda, M., Ribeirinho, M., \& Maguas, C. (2007). Application of solid-phase extraction to brewed coffee caffeine organic acid determination by UV/HPLC. Journal of Food Composition and Analysis, 20(5), 440-448. http://dx.doi.org/10.1016/j.jfca.2006.08.005

Sarrazin, C., Le Quere, J., Gretsch, C., \& Liardon, R. (2000). Representativeness of coffee aroma extracts: a comparison of different extraction methods. Food Chemistry, 70(1), 99-106. http://dx.doi.org/10.1016/S0956-7135(99)00116-4

Sfredo, M. A., Finzer, J. R. D., \& Limaverde, J. R. (2005). Heat and Mass transfer in coffee fruits drying. Journal of Food Engineering, 70(1), 15-25. http://dx.doi.org/10.1016/j.jfoodeng.2004.09.008

Silva, E. M., Rogez, H., \& Larondelle, Y. (2007). Optimization of extraction of phenolics from Inga edulis leaves using response surface methodology. Separation and Purification Technology, 55(3), $381-387$. http://dx.doi.org/10.1016/j.seppur.2007.01.008 
Smith, A. (2002). Effects of caffeine on human behavior, Food and Chemical Toxicology, 40(9), 1243-1255. http://dx.doi.org/10.1016/S0278-6915(02)00096-0

Wang, H., Chen, L., Xu, Y., Zeng, Q., Zhang, X., Zhao, Q., \& Ding, L. (2011). Dynamic microwave-assisted extraction coupled on-line with clean-up for determination of caffeine in tea. LWT - Food Science and Technology, 44(6), 1490-1495. http://dx.doi.org/10.1016/j.tifs.2005.12.004

Wang, L., \& Weller, C. L. (2006). Recent advances in extraction of nutraceuticals from plants. Trends in Food Science \& Technology, 17(6), 300-312.

\section{Nomenclature}

\begin{tabular}{|c|c|}
\hline DIC & Détente InstantanéeContrôlée (French for "Instant controlled pressure drop") \\
\hline GCB & Green coffee bean \\
\hline RSM & Response Surface Method \\
\hline $\mathrm{P}$ & DIC saturated steam pressure (in MPa) \\
\hline $\mathrm{t}$ & DIC thermal treatment time \\
\hline $\mathrm{W}$ & Initial moisture content of GCB \\
\hline$D_{\text {eff }}$ & $\begin{array}{l}\text { Effective diffusivity from the diffusion/surface interaction kinetic model of hot air drying after DIC } \\
\text { treatment }\end{array}$ \\
\hline$\delta \mathrm{W}_{\mathrm{s}}$ & $\begin{array}{l}\text { Starting accessibility from the diffusion/surface interaction kinetic model of hot air drying after DIC } \\
\text { treatment }\end{array}$ \\
\hline $\mathrm{db}$ & Dry basis \\
\hline $\mathrm{p}_{\mathrm{c}}$ & Partial pressure of volatile compounds \\
\hline $\mathrm{R}$ & Gas constant, $\left(8.314 \mathrm{~J} \mathrm{~mol}^{-1} \mathrm{~K}^{-1}\right)$ \\
\hline $\mathrm{T}$ & Temperature $(\mathrm{K})$ \\
\hline$\lambda_{\text {eff }}$ & Effective heat conductivity $\left(\mathrm{W} \mathrm{m}^{-1} \mathrm{~K}^{-1}\right)$ \\
\hline$<\mathrm{M}_{\mathrm{c}}>$ & Averageof molar mass of volatile compounds \\
\hline$<\mathrm{L}_{\mathrm{c}}>$ & Averagelatent heat Length of volatile compounds \\
\hline $\mathrm{v}_{\mathrm{c}}$ & Velocity of volatile compound flux \\
\hline$P$ & Total pressure \\
\hline $\mathrm{K}$ & Darcy coefficient $\left(\mathrm{m}^{2}\right)$ \\
\hline $\mathrm{m}_{\mathrm{m}}$ & Mass of vapor removed \\
\hline $\mathrm{R}_{\mathrm{o}}$ & Poreradius \\
\hline $\mathrm{P}_{\mathrm{o}}$ & Internal total pressure \\
\hline $\mathrm{P}_{\mathrm{ext}}$ & Externaltotal pressure \\
\hline $\mathrm{W}_{\infty}$ & Equilibrium moisture content \\
\hline $\mathrm{W}_{\mathrm{o}}$ & Computed initial moisture content (hypothesis of diffusion model) \\
\hline $\mathrm{W}$ & Moisture content at certain drying time \\
\hline $\mathrm{k}$ & Drying rate \\
\hline $\mathrm{t}$ & Drying time \\
\hline cte & Constant \\
\hline $\mathrm{d}_{\mathrm{p}}$ & Sphere radius \\
\hline$\rho$ & Density of water $\left(\mathrm{kg} \mathrm{m}^{-3}\right)$ \\
\hline
\end{tabular}


Table 1. HPLC elution conditions

\begin{tabular}{|l|l|}
\hline $\begin{array}{l}\text { Solvent gradient (acetic acid } 6.7 \%: \text { acetonitrile } \%: \text { water } \%, \\
\mathrm{v} / \mathrm{v} / \mathrm{v})\end{array}$ & Time (min.) \\
\hline $10.0 \%: 0.0 \%: 90 \%$, & 0 \\
\hline $10.8 \%: 0.2 \%: 89 \%$ & 2 \\
\hline $11.0 \%: 1.0 \%: 88 \%$ & 6 \\
\hline $11.0 \%: 2.0 \%: 87 \%$ & 10 \\
\hline $11.0 \%: 4.0 \%: 85 \%$ & 15 \\
\hline $12.0 \%: 8.0 \%: 80 \%$ & 20 \\
\hline $12.0 \%: 0.0 \%: 88 \%$ & 25 \\
\hline $10.0 \%: 0.0 \%: 90 \%$ & 40 \\
\hline
\end{tabular}

Table 2. Independent variables and their coded and natural levels employed in a 5-level central composite design to optimize the effect of DIC on decaffeination and on drying kinetics of the green coffee beans

\begin{tabular}{|c|c|c|c|c|c|c|}
\hline & \multicolumn{5}{|c|}{ DIC parameters } \\
\hline Trial & Saturated steam pressure $\mathrm{P}$ & \multicolumn{2}{c|}{ Water content dry basis W } & \multicolumn{2}{c|}{ Total processing time t } \\
\hline $\mathrm{N}^{\circ}$ & Coded level & $\begin{array}{c}\text { Natural level } \\
(\mathrm{MPa})\end{array}$ & Coded level & $\begin{array}{c}\text { Natural level } \\
(\% \mathrm{db})\end{array}$ & $\begin{array}{c}\text { Coded level } \\
\text { Natural level } \\
(\mathrm{s})\end{array}$ \\
\hline 1 & $+\alpha$ & 0.6 & 0 & $23.00 \%$ & 0 & 50 \\
\hline 2 & 0 & 0.35 & 0 & $23.00 \%$ & $+\alpha$ & 84 \\
\hline 3 & 0 & 0.35 & 0 & $23.00 \%$ & 0 & 50 \\
\hline 4 & +1 & 0.5 & +1 & $30.00 \%$ & +1 & 70 \\
\hline 5 & 0 & 0.35 & $+\alpha$ & $35.00 \%$ & 0 & 50 \\
\hline 6 & 0 & 0.35 & 0 & $23.00 \%$ & 0 & 50 \\
\hline 7 & +1 & 0.5 & +1 & $30.00 \%$ & -1 & 30 \\
\hline 8 & +1 & 0.5 & -1 & $16.00 \%$ & +1 & 70 \\
\hline 9 & 0 & 0.35 & 0 & $23.00 \%$ & 0 & 50 \\
\hline 10 & +1 & 0.5 & -1 & $16.00 \%$ & -1 & 30 \\
\hline 11 & -1 & 0.2 & +1 & $30.00 \%$ & +1 & 70 \\
\hline 12 & 0 & 0.35 & 0 & $23.00 \%$ & 0 & 50 \\
\hline 13 & -1 & 0.2 & +1 & $30.00 \%$ & -1 & 30 \\
\hline 14 & -1 & 0.2 & -1 & $16.00 \%$ & +1 & 70 \\
\hline 15 & 0 & 0.35 & 0 & $23.00 \%$ & 0 & 50 \\
\hline 16 & 0 & 0.35 & $-\alpha$ & $11.00 \%$ & 0 & 50 \\
\hline 17 & $-\alpha$ & 0.1 & 0 & $23.00 \%$ & 0 & 50 \\
\hline 18 & 0 & 0.35 & 0 & $23.00 \%$ & 0 & 50 \\
\hline 19 & -1 & 0.2 & -1 & $16.00 \%$ & -1 & 30 \\
\hline 20 & 0 & 0.35 & 0 & $23.00 \%$ & $-\alpha$ & 16 \\
\hline 21 & 0 & 0.35 & 0 & $23.00 \%$ & 0 & 50 \\
\hline & & & & & & \\
\hline
\end{tabular}




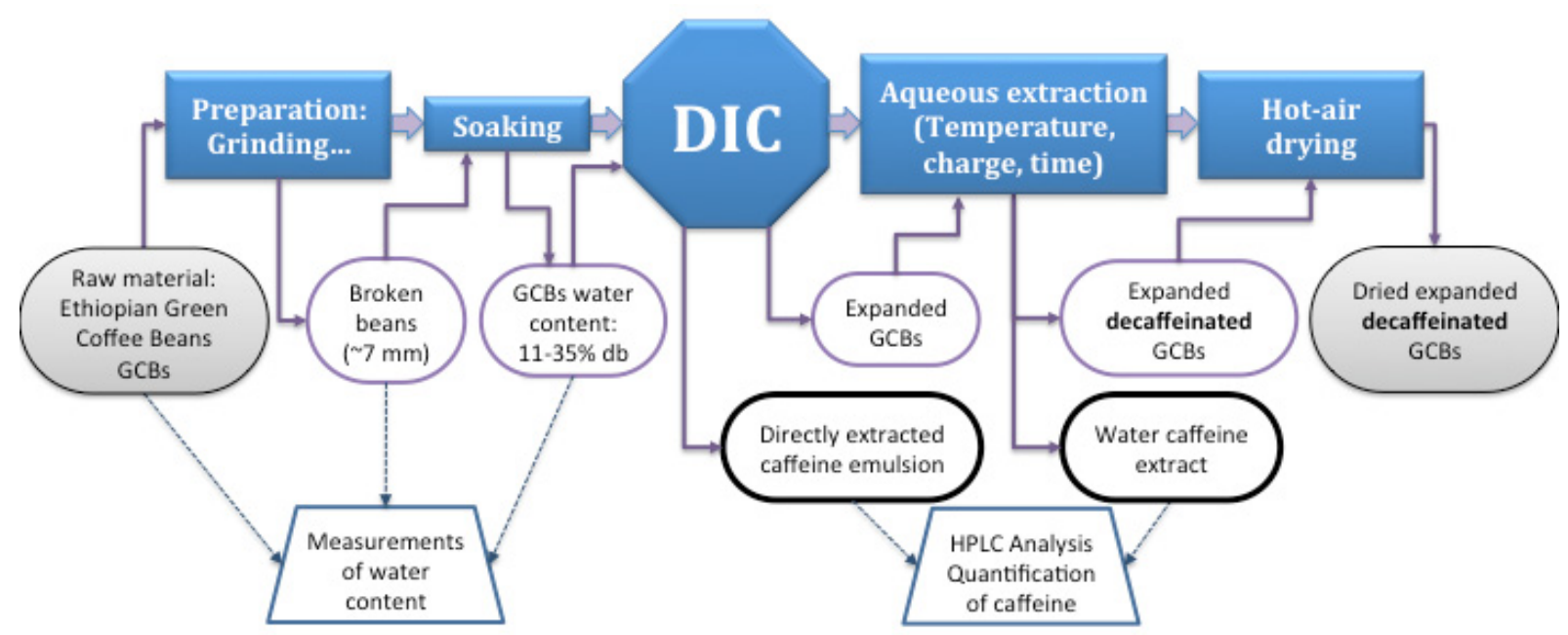

Figure 1. Treatment protocol and assessments of GCBs (Green Coffee Beans) through instant controlled pressure drop DIC

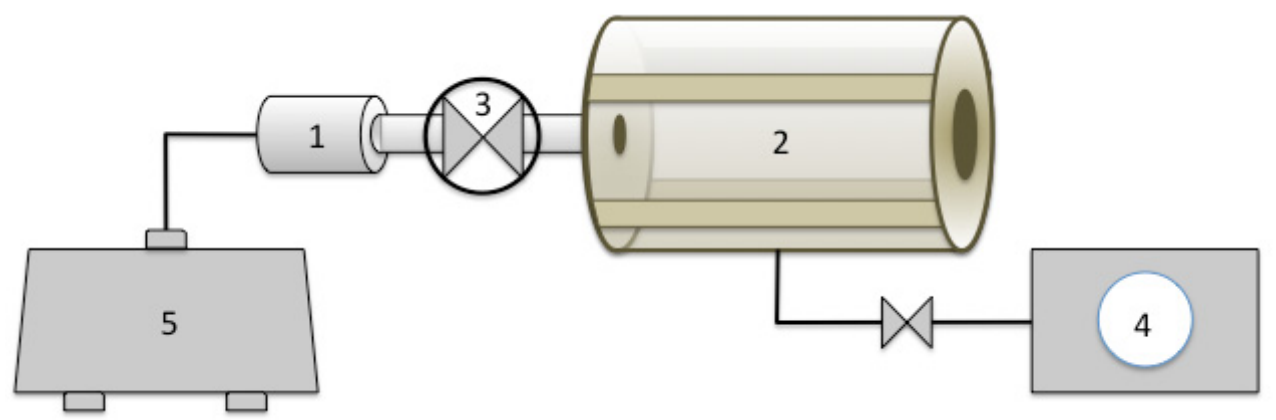

Figure 2. Schematic presentation of DIC reactor: 1- treatment vessel; 2- vacuum tank with transparent Jacket; 3controlled instant pressure drop valve; 4- water ring vacuum pump; 5- steam generator 


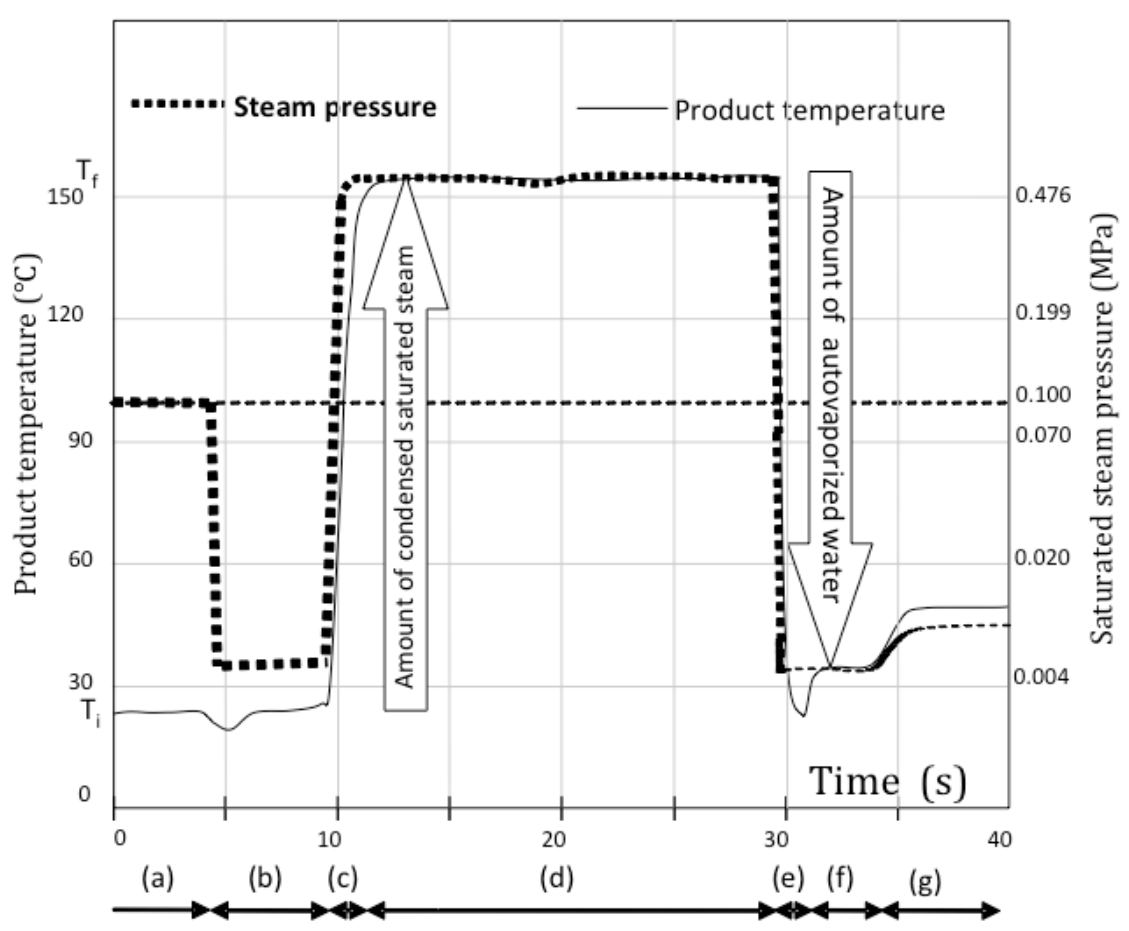

Figure 3. Different stages of a DIC treatment: a- Product to be place in the treatment vessel; b- First vacuum stage; c- saturated steam to be injected in the treatment vessel; d- High-pressure/high-temperature stage; e- Pressure to be abruptly dropped toward a vacuum; f- Second vacuum stage; g- Releasing toward Atmospheric pressure 

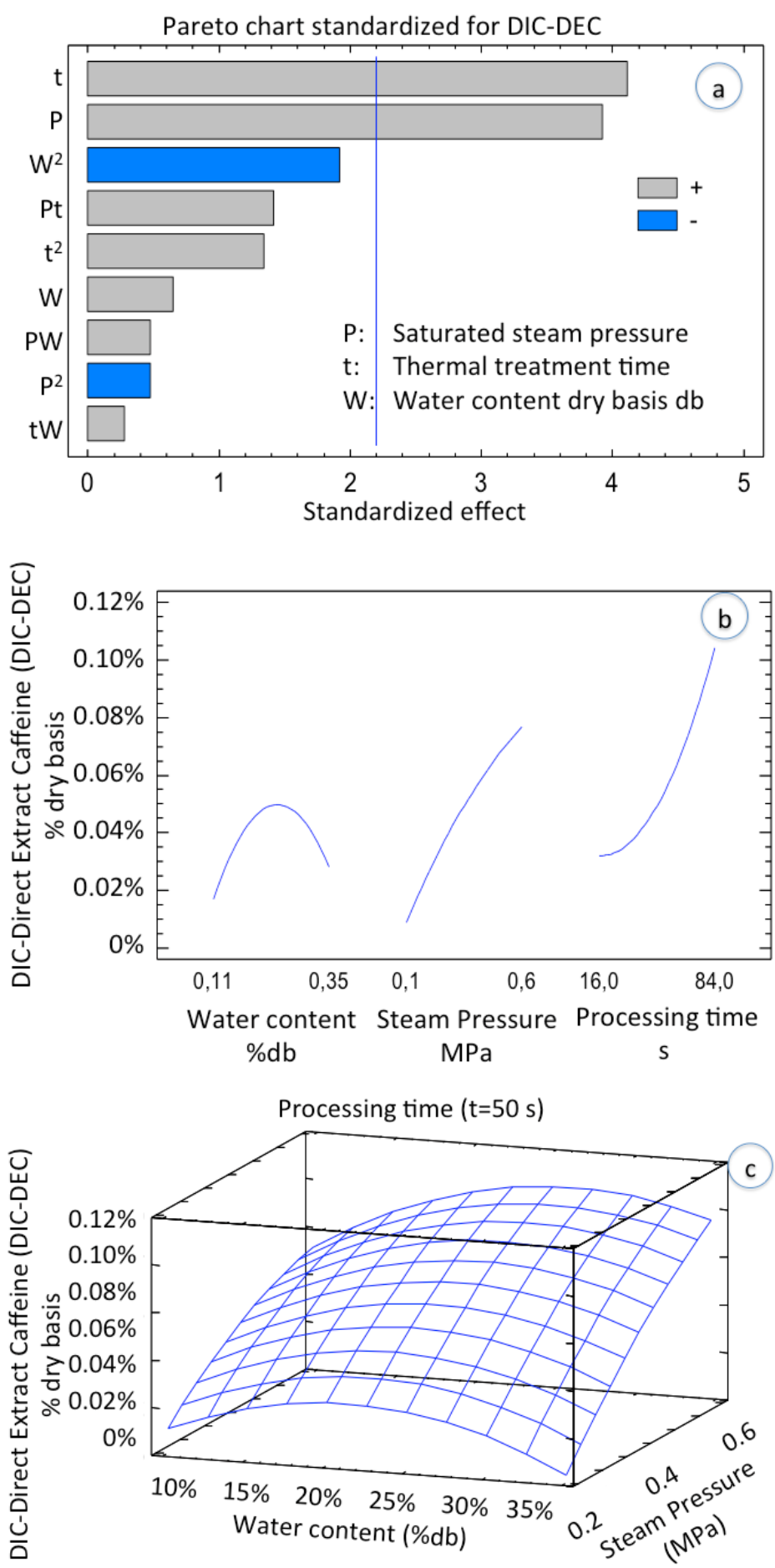

Figure 4. Pareto chart of DIC operating parameters (a), general trends (b), and response surface (c) for caffeine directly extracted by DIC (DIC-DEC) 

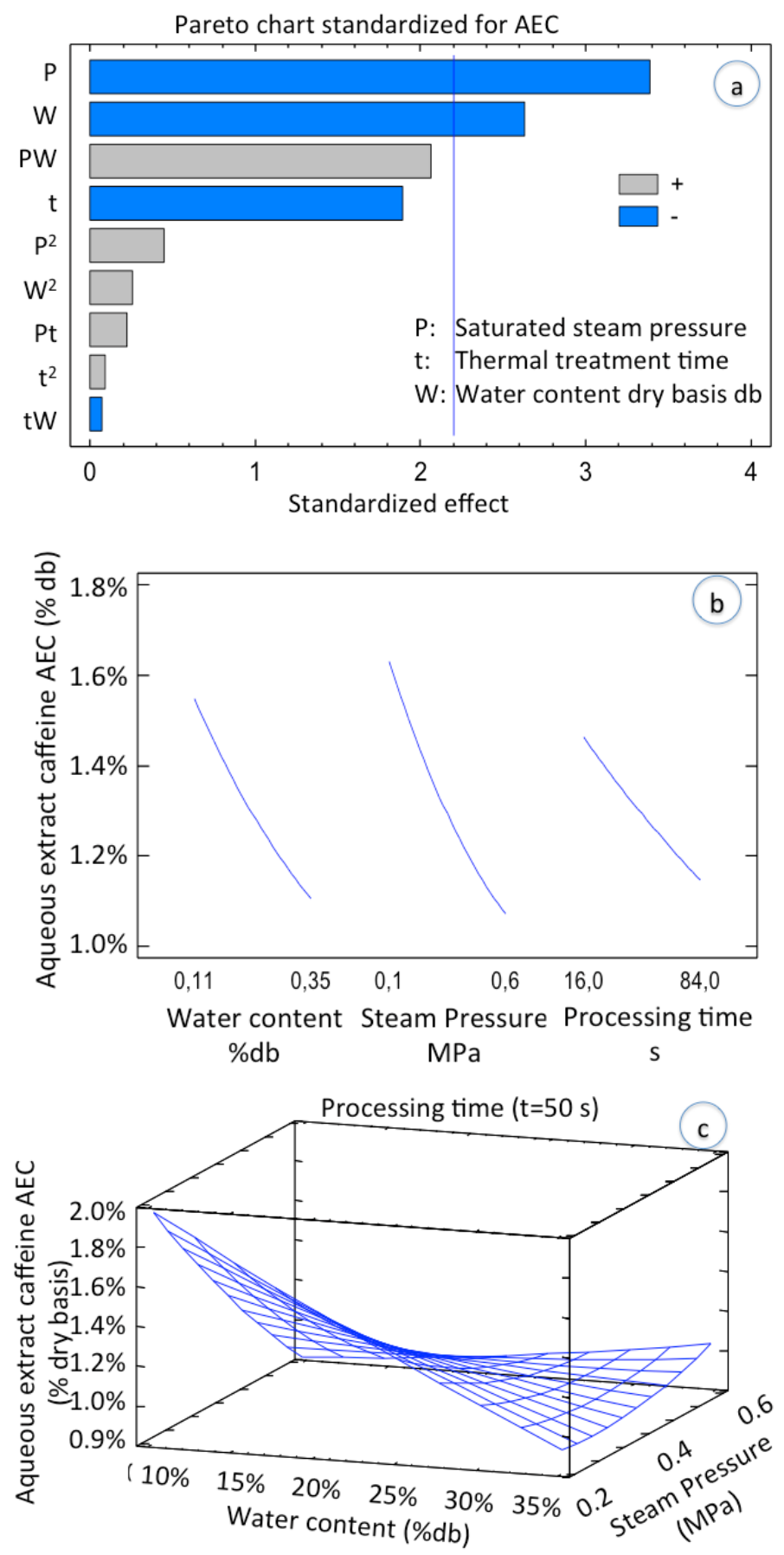

Figure 5. Pareto chart (a), general trends (b) and response surface (c) of DIC operating parameters for caffeine extracted during 20 minutes in water at $97^{\circ} \mathrm{C}$, after DIC treatments (AEC) 

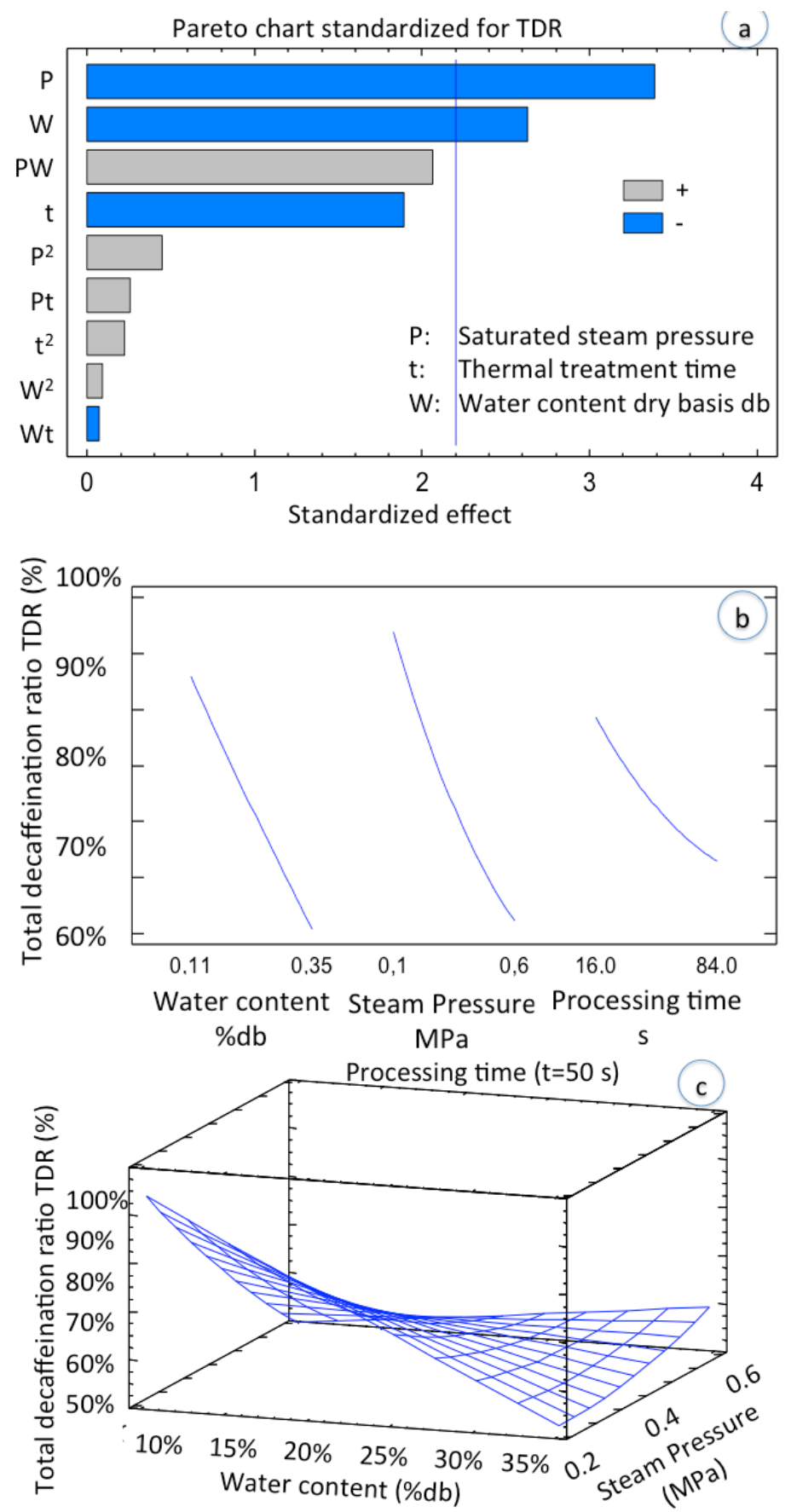

Figure 6. Pareto chart, General trends, and response surface analysis results for total decaffeination ratio (TDR) 

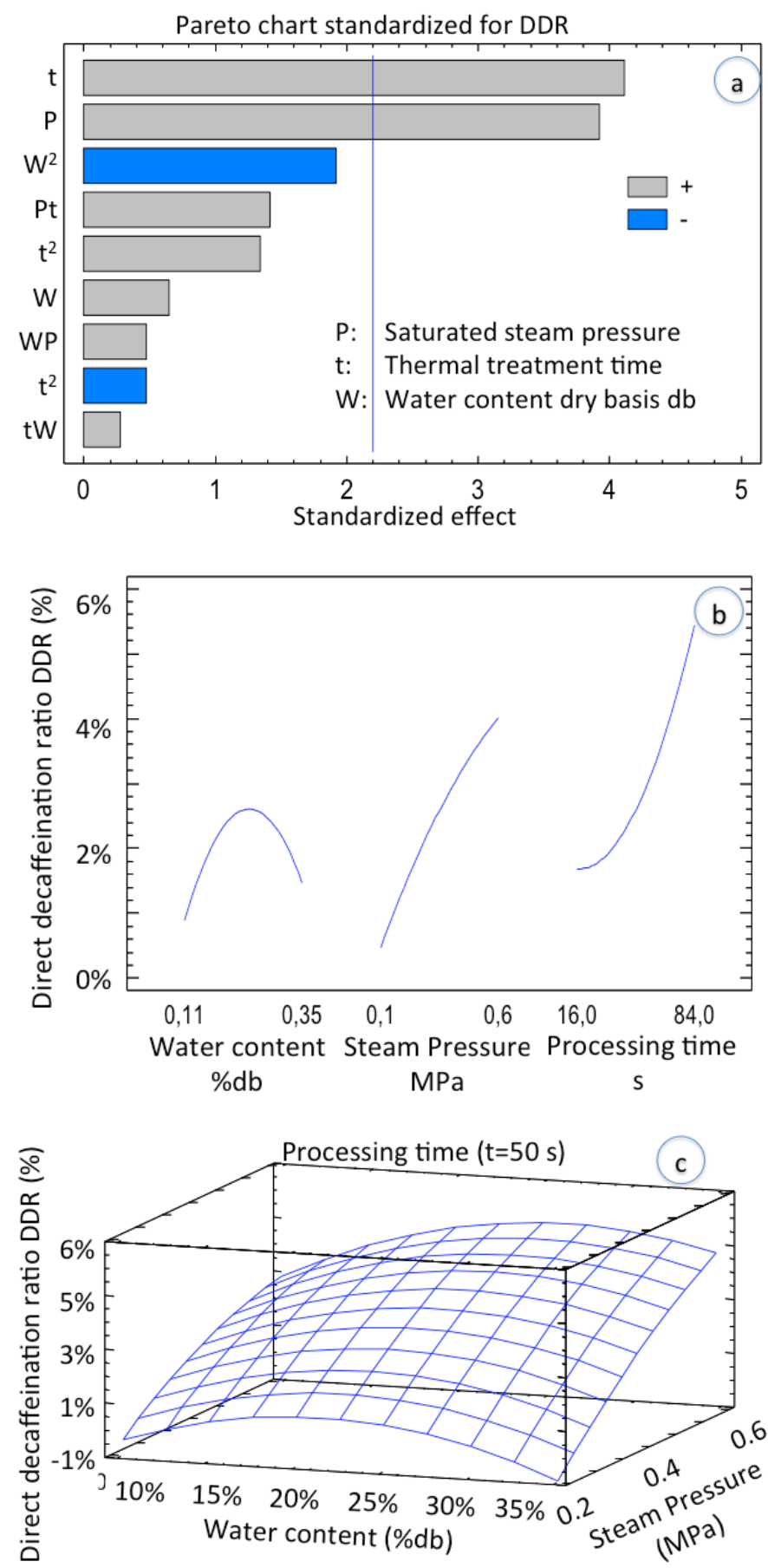

Figure 7. Pareto chart, general trends, and response surface for the DIC-Direct Decaffeination Ratio DDR 

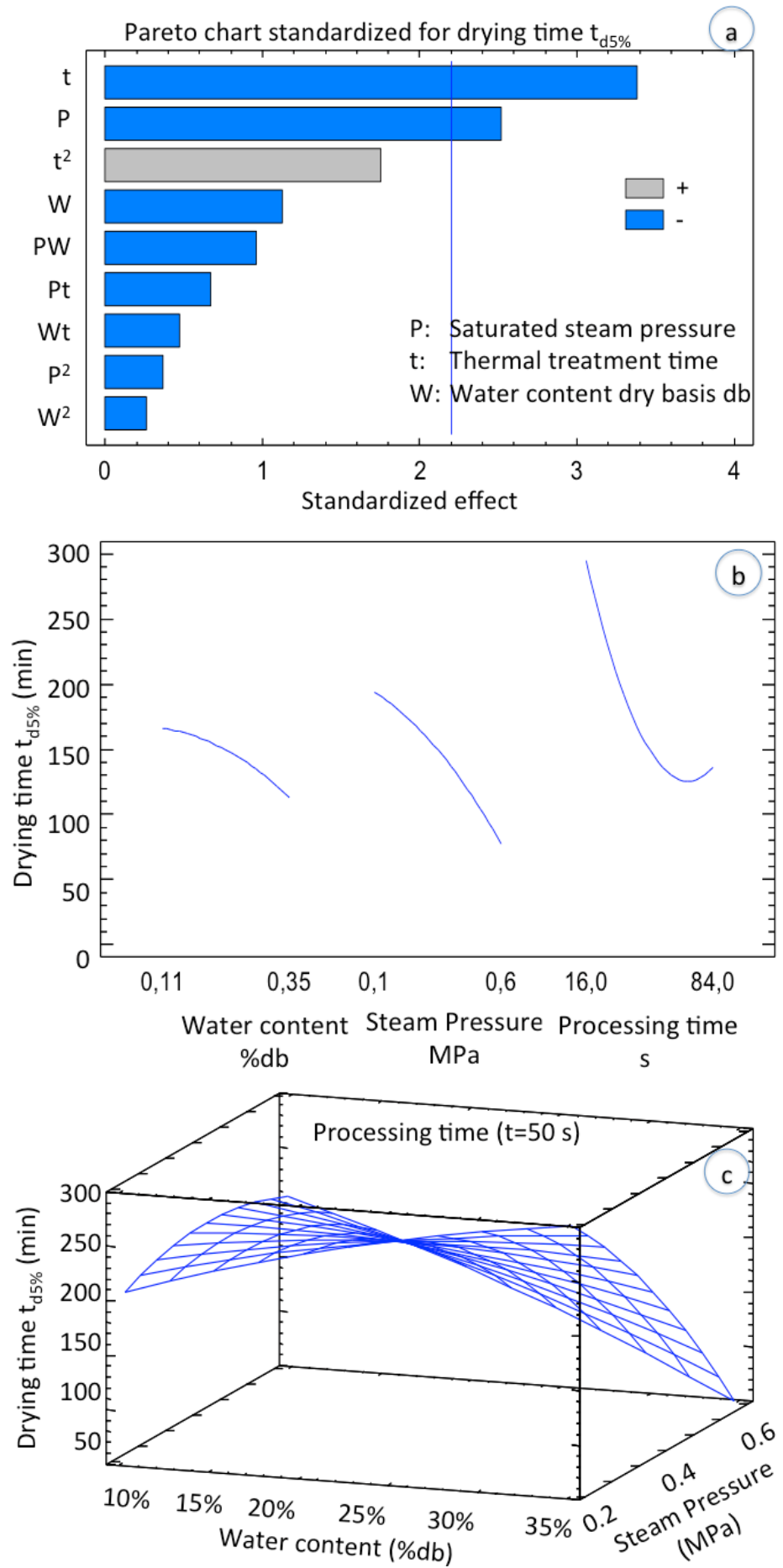

Figure 8. Pareto chart, general trends, and response surface for the drying time t5\% of DIC treated GCBs 

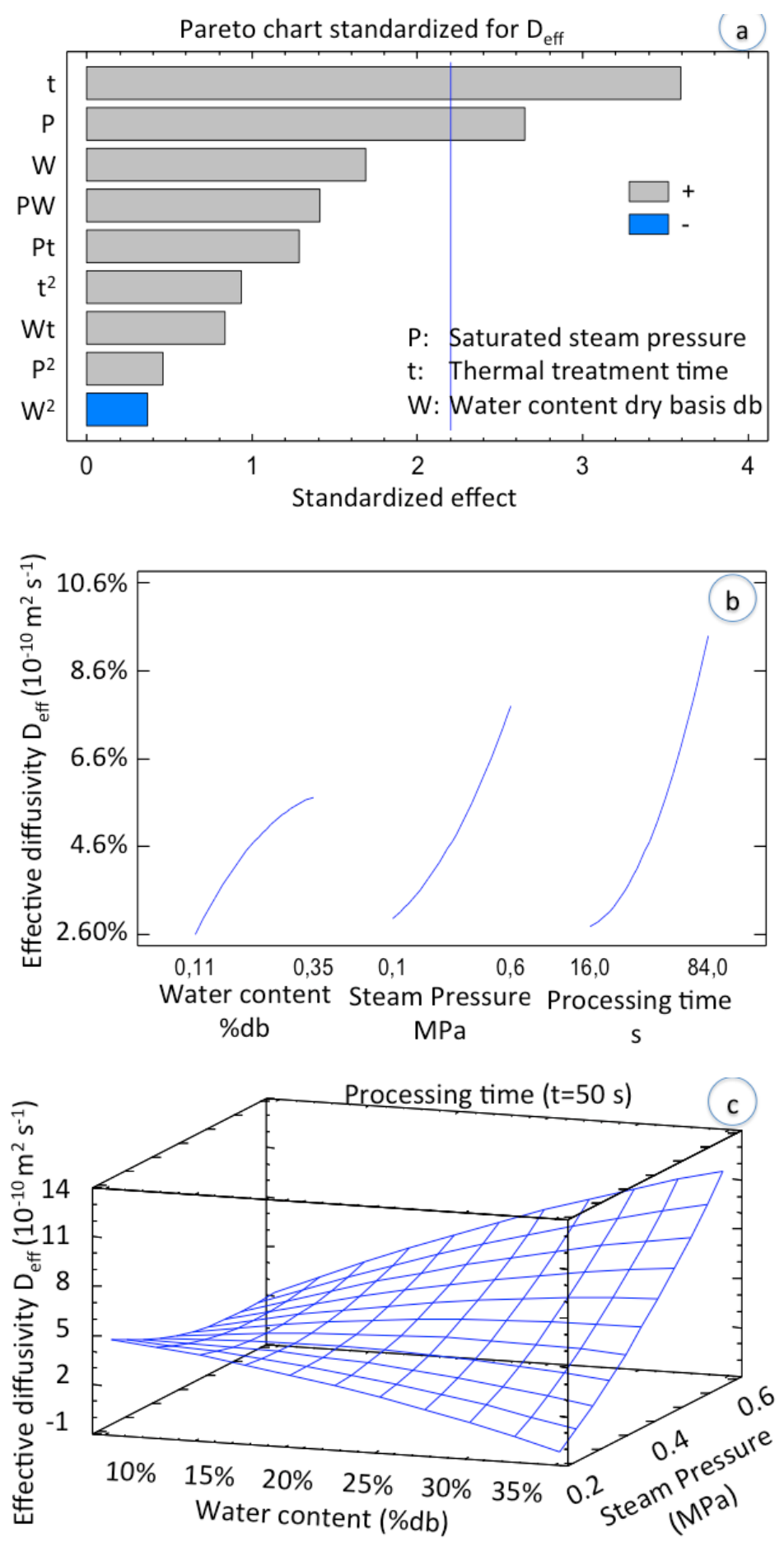

Figure 9. Pareto charts, general trends and response surfaces showing the effects of the DIC processing variables on the effective diffusivity $\mathrm{D}_{\text {eff }}$ 

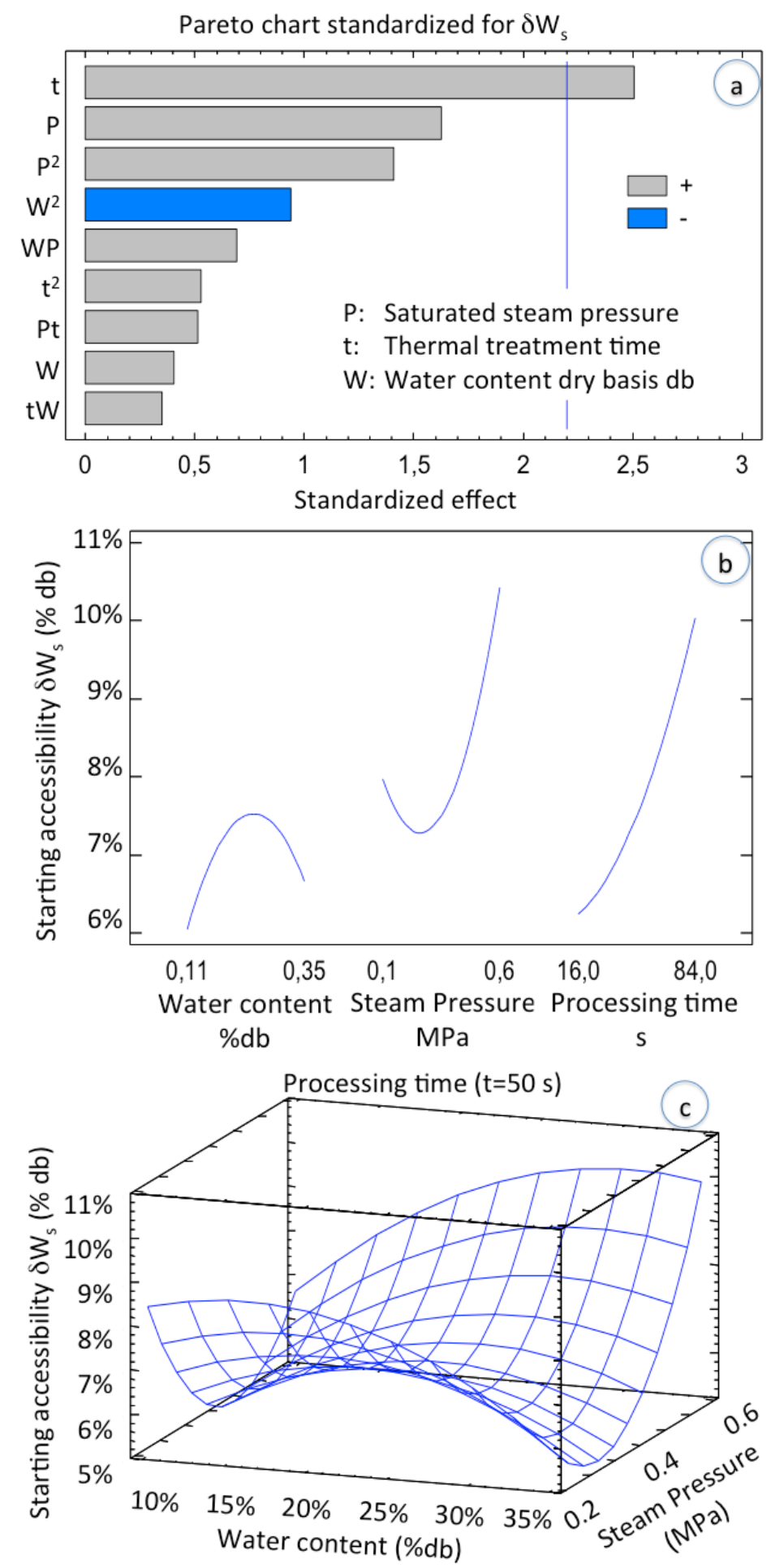

Figure 10. Pareto charts, general trends and response surfaces showing the effects of the DIC processing variables on the starting accessibility $\mathrm{W}_{\mathrm{s}}$ 


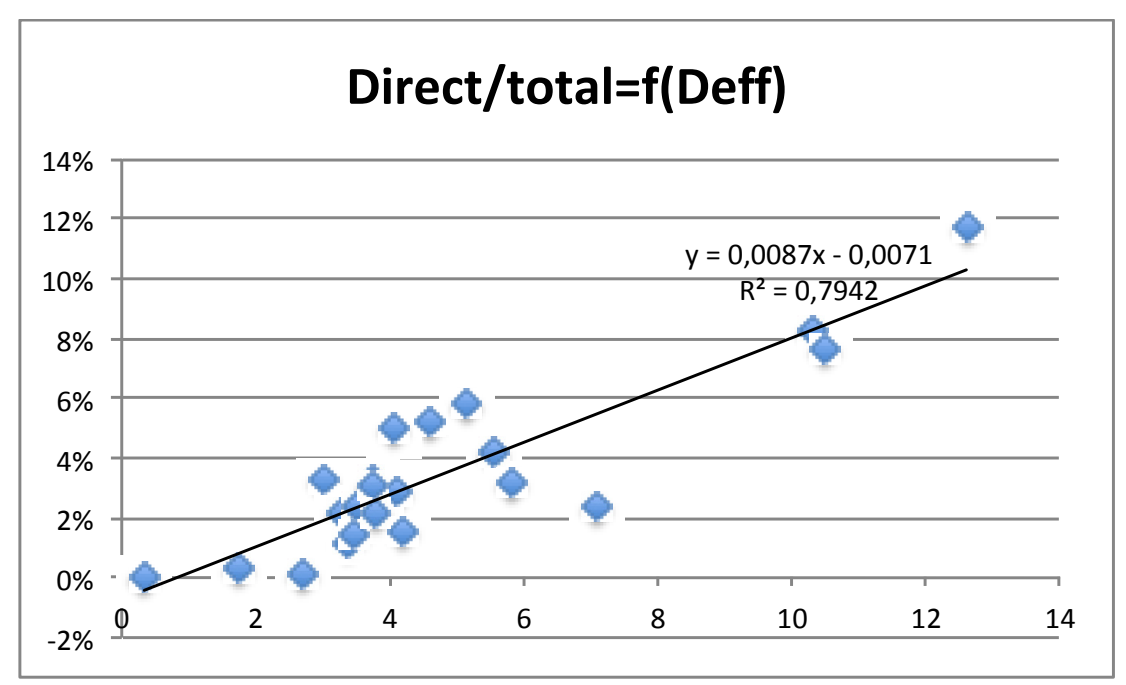

Figure 11. Correlation between drying effective diffusivity and DIC direct decaffeination to total decaffeination ratio (DDR) 